\title{
Erratum to: Simulation of Low-High Transition by Neutral Beam Injection in Edge Plasma of Small Size Divertor Tokamak
}

\author{
A. H. Bekheit
}

Published online: 6 June 2012

(C) Springer Science+Business Media, LLC 2012

Erratum to: J Fusion Energ

DOI 10.1007/s10894-012-9544-2

In the original version of this paper, the author name was incorrect. The correct name of the author is A. H. Bekheit.

The online version of the original article can be found under doi: 10.1007/s10894-012-9544-2.

\footnotetext{
A. H. Bekheit $(\square)$

Plasma and Nuclear Fusion Department, Nuclear Research

Centre, Atomic Energy Authority, Cairo, Egypt

e-mail: amrbekheitga@yahoo.com
} 